\title{
Gas outburst with sediments because of tetrahydrofuran hydrate dissociation
}

\author{
Xuhui Zhang ${ }^{1, *, \dagger}$, Xiaobing $\mathrm{Lu}^{1}$ and Ming $\mathrm{Xiao}^{2}$ \\ ${ }^{1}$ Institute of Mechanics, Chinese Academy of Sciences, Beijing 100190, China \\ ${ }^{2}$ The Pennsylvania State University, Department of Civil and Environmental Engineering, University Park, PA 16802, \\ USA
}

\begin{abstract}
SUMMARY
Methane hydrate $(\mathrm{MH})$ is a new energy resource in the $21^{\text {st }}$ century. But the dissociation of $\mathrm{MH}$ from sediments during the $\mathrm{MH}$ exploration or oil/gas exploration under a hydrate layer accompanied by the softening of soils and formation of excess pore gas pressure may lead to ground failures and environmental disasters. In this study, experiments on modeling the weakening and failure of the sediment by heat-induced dissociation of tetrahydrofuran (THF) hydrate were presented. The failure mode of gas outburst was observed. Gas outbursts is a process where gas and soils in hydrate-dissociation zone burst out after the continuous skeleton of over-layer is fractured during the expansion of the dissociation zone and the formation of gas zone and excess pore gas pressure. An analytical method is presented by decoupling heat transfer and soil deformation. The geometrical and mechanical similarities for gas outburst are obtained. An empirical criterion for the occurrence of outburst is proposed using the theory of thermal conduction, rigid plastic mechanics, and the experimental data. Copyright (C) 2015 John Wiley \& Sons, Ltd.
\end{abstract}

Received 14 January 2013; Revised 5 February 2015; Accepted 17 February 2015

KEY WORDS: hydrate-bearing sediment; THF hydrate; excess pore gas pressure; hydrate dissociation front; outburst

\section{INTRODUCTION}

Hydrate is a crystalline ice-like solid that is composed of guest molecules such as methane, carbon dioxide, THF, sulfur dioxide, and water molecules. In the nature, gas hydrates, mainly methane hydrate, distribute extensively in permafrost and marine sediments under proper conditions of high pressure and low temperature [1-5]. Generally, $1 \mathrm{~m}^{3}$ methane gas hydrate releases about $164 \mathrm{~m}^{3}$ methane gas and $0.2 \mathrm{~m}^{3}$ water at the condition of $1 \mathrm{~atm}$ and $273.15 \mathrm{~K}$. The strength of hydratebearing sediments (HBS) reduces greatly after hydrate dissociation because of the decrease of the adhesion between the hydrate and soil. If hydrate is not dissociated using pore pressure control (i.e. depressurization), an excess pore pressure of more than $40 \mathrm{MPa}$ can form and increase with hydrate fraction and sediment stiffness [6,7].

In hydrate exploration or oil and gas recovery with a hydrate over-layer, heat transfer can lead to hydrate dissociation, expansion of dissociation zone, generation of excess pore gas pressure, seepage of gas and water, and deformation of soil. These may lead to geological disasters such as marine landslide, seabed subsidence, destruction of ocean platforms and oil wells, and even gas blowouts

*Correspondence to: Xuhui Zhang, Key laboratory of Fluid-Solid Coupling System Mechanics, Institute of Mechanics, Chinese Academy of Sciences, China.

†E-mail: zhangxuhui@imech.ac.cn

Contract/grant sponsor: National Natural Science Foundation of China; contract/grant numbers: 11102209, 51239010

Copyright () 2015 John Wiley \& Sons, Ltd. 
[6-12]. It was reported that the Storegga landslide on the Norwegian continental shelf, the largest landslide in the world involving $2500-3200 \mathrm{~km}^{3}$ sediments, was caused by thermal dissociation of gas hydrate [13-15]. The 2010 Deepwater Horizon explosion in the Gulf of Mexico might be caused by dissociation of gas hydrate because the drill rig had reached the sediments where the pressure and temperature were suitable for hydrate formation [16].

Recently, some fully coupled analytical models were presented for methane hydrate extraction, which coupled hydrate dissociation, gas and water flow, heat conduction, and soil deformation [17-21]. These models considered the changes of permeability, effective porosity, modulus of elasticity, and strength during hydrate dissociation; meanwhile elasto-plastic constitutive model for soil deformation and Mohr-Coulomb criterion for soil shearing failure were used. The results showed that soil softening, settlement, and shearing failure could occur accompanying hydrate dissociation expansion $[17,20,21]$. However, most of the theoretical models have difficulty in obtaining the analytical solutions, and the simulation results need to be verified by laboratory or in-situ data. Furthermore, the initiation and patterns of the sediment failure caused by hydrate dissociation have not been reported.

The THF sediments are often adopted as a good substitute for methane hydrate in laboratory experiments. A large volume of THF sediment can be synthesized more safely and economically than methane hydrate sediment, because THF is completely miscible with water in all proportions and forms hydrate at atmosphere and normal temperature [22, 23]. The THF hydrate has a density of $0.97 \mathrm{~g} / \mathrm{cm}^{3}$, close to that of methane hydrate, $0.92 \mathrm{~g} / \mathrm{cm}^{3}$ [24].

Gas outburst with sediments was discovered in laboratory thermal simulation of THF hydrate dissociation and resulted in damage of overlying stratum [12]. The objectives of this paper are: (i) to study the mechanism of outburst failures caused by heat-induced dissociation of THF hydrate sediments; (ii) to present a simplified method of predicting the initiation of gas outburst failure. The sequence of events is illustrated, and a group of decoupled analytical equations are presented to describe heat transfer considering hydrate dissociation, soil deformation, and damage. Critical failure conditions are presented in comparison with experimental results.

\section{PHYSICAL DESCRIPTION OF GAS OUTBURST}

Let us consider the problem of a geometrical scale of well or pipe, where there exists a weak zone around, the soil layer are impermeable initially, and the thickness of overlying layer is small. The physical process of the heat-induced evolution of gas outburst within sediments can be expressed as follows:

(1) Because of the thermal source disturbance, heat transfer leads to the dissociation of THF hydrate sediment sand phase transfer into water, liquid THF, and gas (steam and gas phase of THF) once the phase equilibrium temperatures are reached. As a result, four different zones form as shown in Figures $1 \mathrm{a}$ and 2.

(2) The released gas and water are constrained in the dissociation zone, and a fraction of gas and water at the dissociation front slowly penetrates to the overlying sediments; in the meantime, excess pore gas pressure, which is the driving force of gas outburst, generates. The effective stress of the dissociation zone reduces greatly and even induces liquefaction of the sediments because of the excess pore pressure and the decrease of cohesion of the soil.

(3) The soil's resistance because of gravity and shear strength of the overlying layer decreases with the expansion of hydrate dissociation as the overlying layer becomes thinner and softening. When both the dissociation zone in the hydrate sediment and the melted zone in the overlying layer expand to a critical extent, the driving force equals or exceeds the resistance.

(4) The plastic failure occurs in the overlying layer and a cylinder hole as a flow path forms. Because the gas energy is large enough to maintain a continuous movement of gas and sediments, gas outburst occurs as shown in Figure $1 b$.

The effects of temperature and thickness of the overlying layer on the occurrence of gas outburst were investigated. Six experiments in a model box with length of $50 \mathrm{~cm}$, height $\mathrm{of} 30 \mathrm{~cm}$, and width 


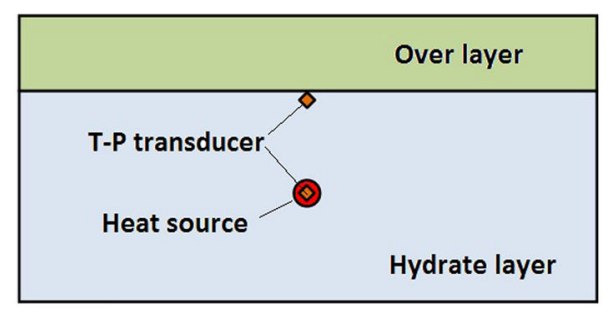

a

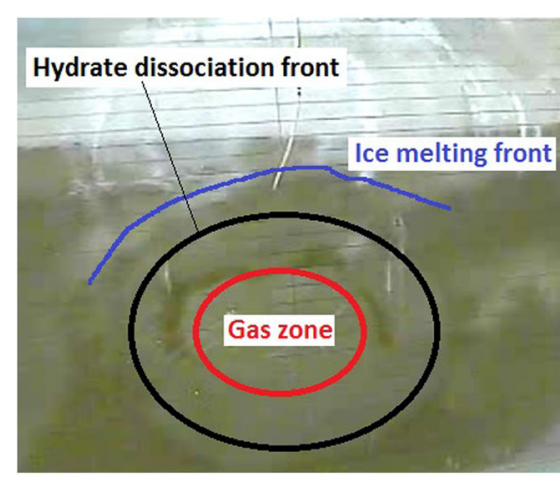

b

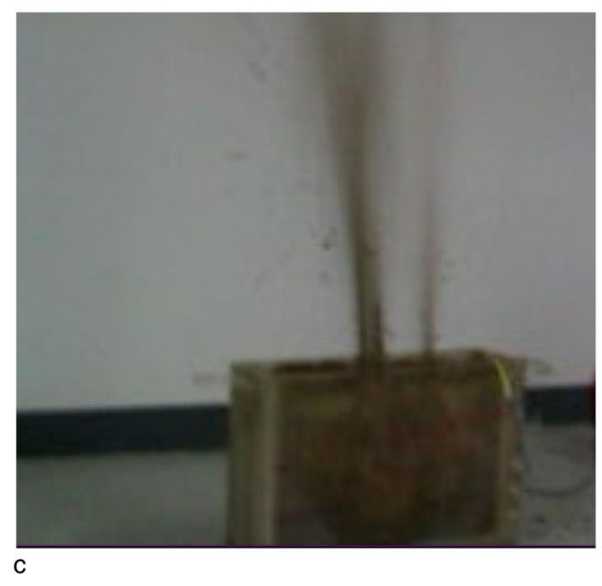

Figure 1. Experimental setups and physical process of gas outburst, a. Setups of experiments, b. Expanding of the dissociation zone, and c. Gas outburst.

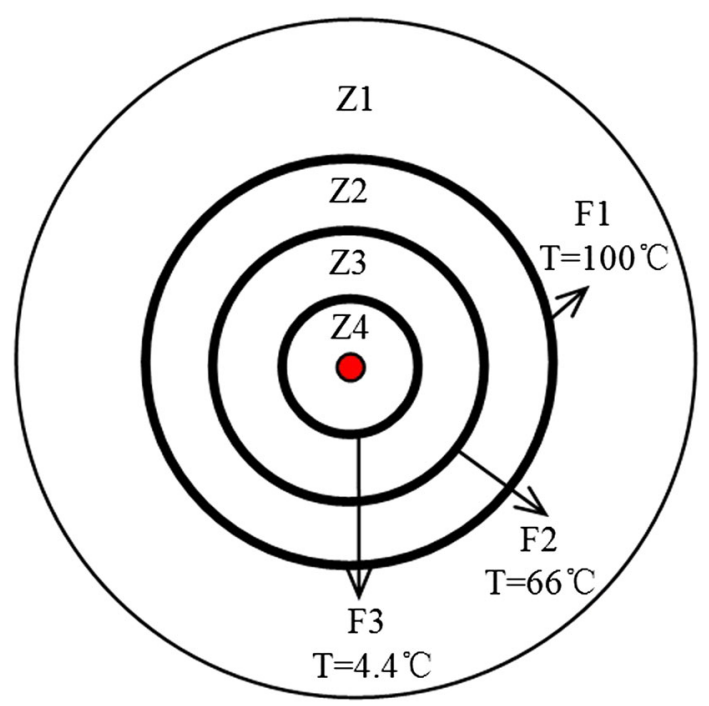

Figure 2. Zones and fronts during hydrate dissociation in sediments. Notes: Z1-Un-dissociated zone consisting of hydrate and sediment skeleton; Z2-Hydrate dissociation zone consisting of liquid, water, and sediment skeleton; Z3-Gasification zone consisting of gas, water and sediment skeleton; Z4-Water vaporization zone consisting of sediment skeleton, water vapor, gas; F1-Hydrate dissociation front; F2-Gasification front; F3-Water vaporization front. The solid red circle indicates the heat source. 
of $10 \mathrm{~cm}$ were conducted with the temperatures designated as $110^{\circ} \mathrm{C}, 112^{\circ} \mathrm{C}, 120^{\circ} \mathrm{C}, 130^{\circ} \mathrm{C}$, and $150^{\circ} \mathrm{C}$, respectively. The hydrate layer was $20 \mathrm{~cm}$ in thickness, and two types of overlying layers, $2 \mathrm{~cm}$ and $5 \mathrm{~cm}$ in thickness, respectively, were set up with sediments containing $90 \%$ saturation of ice. The heat source (a cylindrical heating rod with a diameter of $1 \mathrm{~cm}$ and a length of $8 \mathrm{~cm}$ ) was placed in the center of the hydrate layer parallel to the width direction to simulate an axial symmetry dissociation of hydrate sediments (as in Figure 1a). $p_{g}-p_{0}$ is the excess pore gas pressure and measured by pressure transducers in experiments. The detailed experimental description, measurements, and relative results were presented by Zhang et al. [12]. The experimental setup and results are listed in Table I. It should be noted that after gas outbursts, the sediments close to the outburst path of the overlying layer are mostly melted and softened.

\section{THEORETICAL ANALYSIS OF GAS OUTBURST}

\subsection{Decoupling method}

Heat transfer, hydrate dissociation, pressure dissipation, and soil deformation are basic physical processes in gas outburst [25]. The characteristic time scales governing the physical processes of gas outburst are:

Heat transfer characteristic time is:

$$
t_{c}^{*}=\rho C l^{2} / \lambda
$$

where $\rho, C, l, \lambda$ are density, specific heat, thickness, and thermal conductivity of hydrate bearing sediment, respectively.

Hydrate dissociation is a process of phase transformation, and the energy is provided by heat transfer. Hydrate dissociation rate is considered in heat transfer without its dissociation kinetics, i.e. when the phase transformation temperature is achieved and the dissociation enthalpy is satisfied, hydrate dissociation occurs immediately.

Pressure dissipation characteristic time is:

$$
t_{s}^{*}=n_{0} c_{t} \mu_{g} l^{2} / K_{g}
$$

where $n_{0}, c_{t}, \mu_{g}, K_{g}$ are porosity, compression coefficient, viscosity, and absolute permeability of hydrate bearing sediment, respectively.

Characteristic time of elastic wave propagation is:

$$
t_{e}^{*}=l / \sqrt{E / \rho}
$$

where $E$ is the elastic modulus of hydrate bearing sediment. Then the elastic wave will propagate through the over layer in a similar period.

Here the sediments before hydrate dissociation are considered to be impermeable, the pore gas and water released by hydrate dissociation distribute in hydrate dissociation zone, and the pore

Table I. Experimental conditions and results.

\begin{tabular}{lcccccc}
\hline \multirow{2}{*}{ Conditions } & \multicolumn{5}{c}{ Tests } \\
\cline { 2 - 7 } & 1 & 2 & 3 & 4 & 5 & 6 \\
\hline Temperature of heat $\left({ }^{\circ} \mathrm{C}\right)$ & 110 & 112 & 120 & 120 & 130 & 150 \\
Thickness of overlying layer $(\mathrm{cm})$ & 2 & 2 & 2 & 5 & 2 & 5 \\
Heating time (min) & 38 & 40.8 & 71.8 & 77 & 44.9 & 72.1 \\
Dissociation length $(\mathrm{cm})$ & 7.5 & 8.0 & 9.8 & 9.0 & 9.0 & 10.8 \\
Excess pore pressure at outburst (MPa) & 0.04 & 0.03 & 0.095 & 0.1 & 0.07 & 0.065 \\
Diameter of holes after outburst & 2.5 & 2 & 2 & 1.5 & 2.5 & 2.5 \\
\hline
\end{tabular}


fluid pressure can be determined by heat transfer and hydrate dissociation. Then the ratio between $t_{c}^{*}$ and $t_{e}^{*}$ is on the magnitude of $10^{9}: 1$ [26]. This means that the problem can be taken as two independent processes, i.e. the heat transfer, the pressure dissipation, and the elastic wave propagation, based on which a simple and practical method is presented below: (i) thermal conduction considering phase transformation in sediment, the slowest and controlling process, is analyzed first; (ii) redistribution of stresses in sediment is analyzed to obtain the initiation and development of the failure of sediment.

\subsection{Heat transfer considering phase transformations}

Heat transfer with phase transformation fronts and different zones in THF hydrate sediments is defined in Figure 2. When the phase equilibrium temperature is reached, a hydrate dissociation zone and a nondissociated zone form and are divided by the dissociation front. Second, the liquid is gasified when the gasification temperature is reached, and a gasification zone forms and is separated from the hydrate dissociation zone by the gasification front. Finally, water is transformed into vapor when the boiling temperature is reached, and the gasification zone and the water vaporization zone are divided by the vaporization front.

In the present model the following assumptions are made: (i) thermodynamic parameters of each phase in every miscible zone are the average values; (ii) the enthalpies of water, liquid, and hydrate are constant. Based on the mixture theory and heat transfer, the axis-symmetrical equation for the thermal dissociation of hydrate is obtained as follows:

Governing equation:

$$
\rho C \frac{\partial T}{\partial t}=K\left(\frac{\partial^{2} T}{\partial r^{2}}+\frac{1}{r} \frac{\partial T}{\partial r}\right)
$$

Initial condition:

$$
t=0, T=T_{0}
$$

Boundary conditions:

$$
\begin{gathered}
r=r_{0}, T=T_{H} \\
r=l, T=T_{0}
\end{gathered}
$$

Connecting conditions at the fronts:

$$
\begin{aligned}
T\left(s_{i}(t)\right) & =T_{D i} \\
\left.K(s+) \frac{\partial T}{\partial r}\right|_{s_{i}+}-\left.K(s-) \frac{\partial T}{\partial r}\right|_{s_{i}-} & =\rho_{i} \Delta H_{i} n_{0} S_{i} \frac{d s_{i}}{d t}
\end{aligned}
$$

Here, $\rho, C, K, n_{0}, S_{i}$, and $\Delta H$ are density, specific heat, thermal conductivity, porosity, saturation, and enthalpy of phase transformation, respectively. Subscript $i$ indicates the fronts of hydrate dissociation, gasification, and water vaporization, respectively. $T_{H}, T_{0}$, and $T_{D i}$ are the temperature of heat source, initial temperature of sediments, and phase transformation temperature of each phase. $s_{i}$ represents the front of phase transformation. $r_{O}$ and $l$ are the diameters of heat source and finite field. $t, r$, and $t$ represent the variables of temperature, space, and time. + and - represent right and left of dissociation front. 
The relations of volume factors:

In $\mathrm{Z}_{1}$ :

$$
S_{h}=1
$$

In $Z_{2}$ :

$$
S_{w}+S_{f}=1, S_{w}=\frac{\rho_{h} S_{h} M_{w}}{\rho_{w} M_{h}} \text { and } S_{f}=\frac{\rho_{h} S_{h} M_{f}}{\rho_{f} M_{h}}
$$

In $\mathrm{Z}_{3}$ :

$$
S_{w}+S_{f g}=1 \text { and } S_{w}=\frac{\rho_{h} S_{h} M_{w}}{\rho_{w} M_{h}}
$$

In $\mathrm{Z}_{4}$ :

$$
S_{w g}+S_{f g}=1
$$

The thermal parameters are written as follows:

$$
\begin{gathered}
\rho C=n_{0} S_{i} \rho_{i} C_{i}+\left(1-n_{0}\right) \rho_{m} C_{m} \\
K=n_{0} S_{i} K_{i}+\left(1-n_{0}\right) K_{m}
\end{gathered}
$$

Here, subscripts $f, w, h, m, w g$, and $f g$ indicate liquid THF, water, hydrate, soil skeleton, water vapor, and gas THF, respectively. $M$ is mole mass. $i$ represents the components in the pore of sediments, i.e. hydrate in $\mathrm{Z}_{1}$, water and liquid THF in $\mathrm{Z}_{2}$, water and gas $\mathrm{THF}$ in $\mathrm{Z}_{3}$, and water vapor and gas THF in $\mathrm{Z}_{4}$. In addition, the specific heat and thermal conductivity of gas are related to temperature and pressure, but the ratios of both $\left(1-n_{0}\right) K_{m} / n_{0} S_{g} K_{g}$ and $\left(1-n_{0}\right) \rho_{m} C_{m} / n_{0} S_{g} \rho_{g} C_{g}$ are about $10^{2}$; the changes with temperature distribution in each zone can be ignored.

Substituting $\theta=\frac{T-T_{0}}{T_{H}-T_{0}}, \kappa=\frac{K}{\rho C}$ into equations 3$)-(8$, the above equations can be rewritten as follows:

Governing equation:

$$
\frac{\partial \theta}{\partial t}=\frac{\kappa}{\kappa_{s}}\left(\frac{\partial^{2} \theta}{\partial r^{2}}+\frac{1}{r} \frac{\partial \theta}{\partial r}\right)
$$

Initial condition:

$$
t=0, \theta=0
$$

Boundary conditions:

$$
r=\frac{r_{0}}{l}, \theta=1
$$




$$
r=1, \theta=0
$$

Connection conditions at fronts:

$$
\theta\left(s_{i}(t)\right)=\frac{\theta_{D i}}{\theta_{h}},\left.\frac{K(s+)}{K_{m}} \frac{\partial \theta}{\partial r}\right|_{s_{i}+}-\left.\frac{K(s-)}{K_{m}} \frac{\partial \theta}{\partial r}\right|_{s_{i}-}=\frac{\kappa_{m} \rho_{i} \Delta H n_{0} S_{i}}{K_{m} \theta_{h}} \frac{d s_{i}}{d t}
$$

A numerical method is presented here to solve equations (15)-(19) to analyze the evolution of the phase transformation fronts in a finite length of hydrate bearing sediments.

Equations (15)-(19) are discretized by using the Crank-Nicolson difference method:

Governing equation:

$\frac{\theta_{j}^{n+1}-\theta_{j}^{n}}{\Delta t}=\frac{\kappa}{\kappa_{m}} \frac{1}{2(\Delta r)^{2}}\left(\theta_{j+1}^{n+1}-2 \theta_{j}^{n+1}+\theta_{j-1}^{n+1}+\theta_{j+1}^{n}-2 \theta_{j}^{n}+\theta_{j-1}^{n}+\frac{1}{2(j+p)}\left(-\theta_{j+1}^{n}+\theta_{j-1}^{n}-\theta_{j+1}^{n+1}+\theta_{j-1}^{n+1}\right)\right)$

where $n$ and $j$ are points of time and space, $j=1,2, \cdots N, p=\frac{r_{0}}{\left(l-r_{0}\right) \Delta r}$, and $\Delta t$ and $\Delta r$ are time step and space step.

Boundary condition:

$$
\begin{aligned}
& \theta_{0}^{n}=1 \\
& \theta_{N}^{n}=0
\end{aligned}
$$

Initial condition:

$$
\theta^{0}=0
$$

Connecting conditions at the transformation fronts:

If the temperature at node $j$ reaches $T_{D i} / T_{D h}$, phase transformation will occur, so the temperature keeps constant until the input of the heat equals the enthalpy for hydrate dissociation, i.e.

$$
\sum_{n}^{n+m}\left(\frac{\theta_{j-1}^{n}-\theta_{j}^{n}}{\Delta r}-\frac{\theta_{j}^{n}-\theta_{j+1}^{n}}{\Delta r}\right) \Delta t=\frac{\rho_{i} \Delta H n_{0} S_{i}}{\rho C \theta_{D h}} \Delta r
$$

The numerical simulation procedures follow: after a duration of $m \cdot \Delta t$, the phase transformation process at node $j$ is finished, then the temperature at node $j+1$ will reach $T_{D i} / T_{D h}$, and the phase transformation will occur at this node. Then the temperature will reach $T_{D i} / T_{D h}$ at $j+2$ until the input of the heat equals the enthalpy for hydrate dissociation at node $j+1$.

The parameters were adopted and listed in Table II. The specific heat of the gas was determined by the formula $C=3 R / M$. The heat conduction coefficient was assumed to be the same as that of water vapor, although it actually changes with temperature.

\subsection{Criterion for gas outburst}

The possible failure mechanisms are soil softening, hydraulic fracturing, cavity expansion, outburst etc. Hydraulic fracturing and cavity expansion depend on the soil strength properties and the depth $[12,27]$. Here, gas outburst is considered as a problem with a scale of well or pipe where exists a 


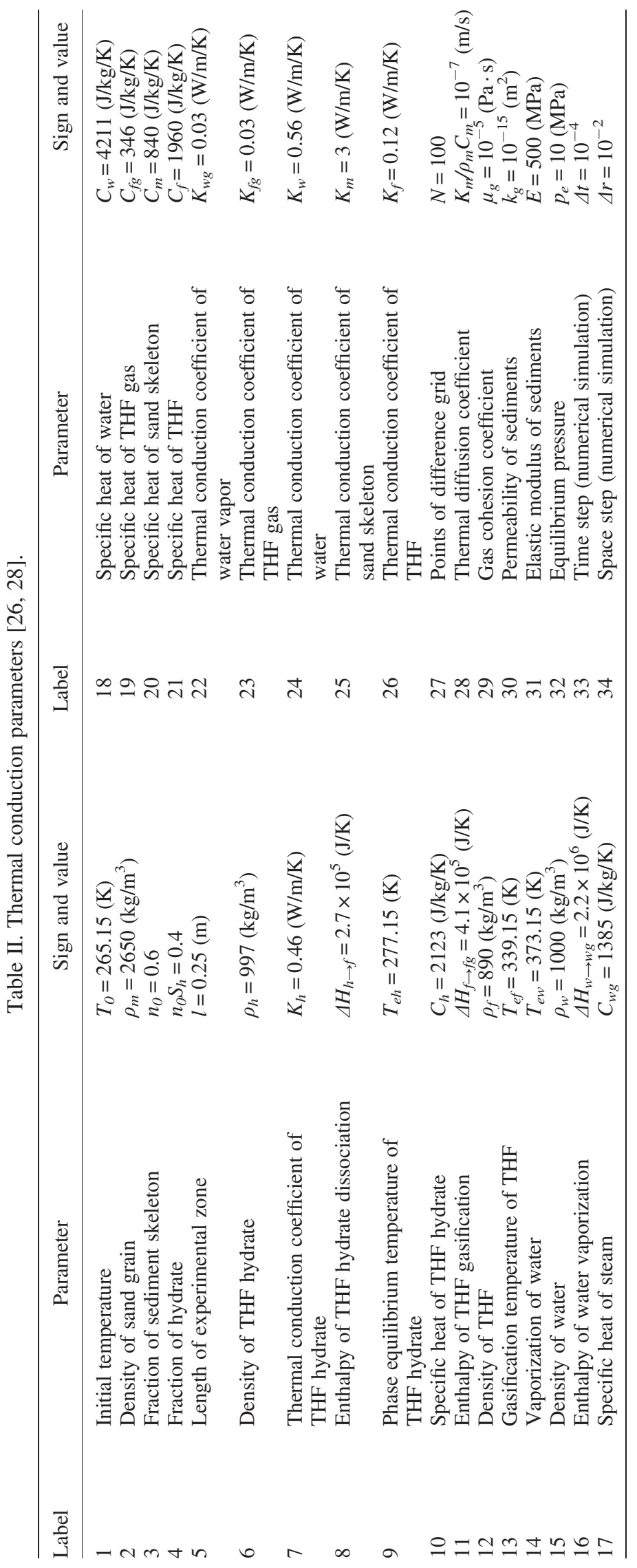


weak zone around. The conditions of the problem are as follows: The dissociated zone is overlain by impermeable layer, and the over-layer and hydrate layer without hydrate dissociation can restrict the pore water or gas in the dissociation zone. An unloading wave transmits into the sediment rapidly in hydrate dissociation zone, and the effective stress reduces greatly. The sediment is softened accompanying a formation of weak zone with the expansion of hydrate dissociation, and gas outburst failure occurs when the dissociation zone is large enough.

The initial parameters for the critical condition of gas outburst include the following: the critical length $R_{c r i}$ at outbursts, the characteristic thickness of hydrate sediments $h$, the specific gravity of overlying layer $\bar{\rho} g$, the pressure above the overlying layer $p_{0}$, the excess pore gas pressure (the driving force of gas outburst) $p_{g}-p_{0}$, and the strength $\tau_{f} \cdot \frac{h}{d}$ of sediments in and around gas outburst path, i.e. the cylinder hole with a diameter $d$.

The dimensions of these parameters are listed in Table III.

Through dimensional analysis, choose $h$ and $p_{g}-p_{0}$ as basic units, the dimensionless relationship can be written as:

$$
f\left(\frac{\bar{\rho} g h}{p_{g}-p_{0}}, \frac{\tau_{f} \cdot h}{\left(p_{g}-p_{0}\right) \cdot d}, \frac{R_{c r i}}{h}\right)=0
$$

where $\frac{R_{c r i}}{h}$ is the ratio of critical outburst radius and thickness of overlying layer during hydrate dissociation, $\frac{\bar{\rho} g h}{p_{g}-p_{0}}$ is the ratio of overlying layer's gravity and excess pore pressure, and $\frac{\tau_{f} \cdot h}{\left(p_{g}-p_{0}\right) \cdot d}$ is the ratio of strength of weak zone in the overlying layer and excess pore pressure. If $\frac{R_{c r i}}{h}$ is large enough or $\frac{\bar{\rho} g h}{p_{g}-p_{0}}$ and $\frac{\tau_{f} \cdot h}{\left(p_{g}-p_{0}\right) \cdot d}$ are small enough, gas outburst failure may occur. The dimensionless parameters control the physical mechanism of gas outburst. The geometric and mechanical similarities in experiments and practice can achieve a similar physical process. The empirical relationship of equation 25 could provide a reference to engineering application in a similarity criterion. First, $\frac{R_{c r i}}{h}$ and $\frac{\bar{\rho} g h}{p_{g}-p_{0}}$ can be estimated theoretically or numerically based on different geometries of hydrate recovery, then $\frac{\tau_{f} \cdot h}{\left(p_{g}-p_{0}\right) \cdot d}$ is checked to determine whether a weak zone exists. Of course, the pore pressure dissipation, the size of dissociation expansion, and soil deformation will affect the speed and strength of gas outburst.

In the gas outburst scenario, a cylindrical hole formed as a flow path in the experiments, and the shear failure are considered as in Figure 3. The sediment in the failure zone is impermeable, and the resistance force within the sediment is undrained shear strength. Because the pore pressure is 100 times of soil's effective stress in the hydrate dissociation zone, the soil liquefies, and the pore pressure is applied directly to the interfaces of sediments as driving force. Two parts containing melting zone and un-melting zone of the overlying layer are assumed. The force that results in the critical outburst is:

$$
F_{D}=\frac{\pi \cdot d^{2}}{4} \cdot\left(p_{g}-p_{0}\right)
$$

Table III. Parameters of outburst failures after hydrate dissociation.

\begin{tabular}{lcl}
\hline Physical variables & Symbol & \multicolumn{1}{c}{ Dimension } \\
\hline Specific gravity & $\bar{\rho} g$ & {$[\bar{\rho} g]=M^{1} L^{-1} T^{-2}$} \\
Characteristic height & $h$ & {$[h]=M^{0} L^{1} T^{0}$} \\
Shear strength & $\tau_{f}$ & {$\left[\tau_{f}\right]=M^{1} L^{-1} T^{-2}$} \\
Excess pore gas pressure & $p_{g}-p_{0}$ & {$\left[p_{g}-p_{0}\right]=M^{1} L^{-1} T^{2}$} \\
Length at outburst & $R_{c r i}$ & {$\left[R_{c r i}\right]=M^{0} L^{1} T^{0}$} \\
\hline
\end{tabular}




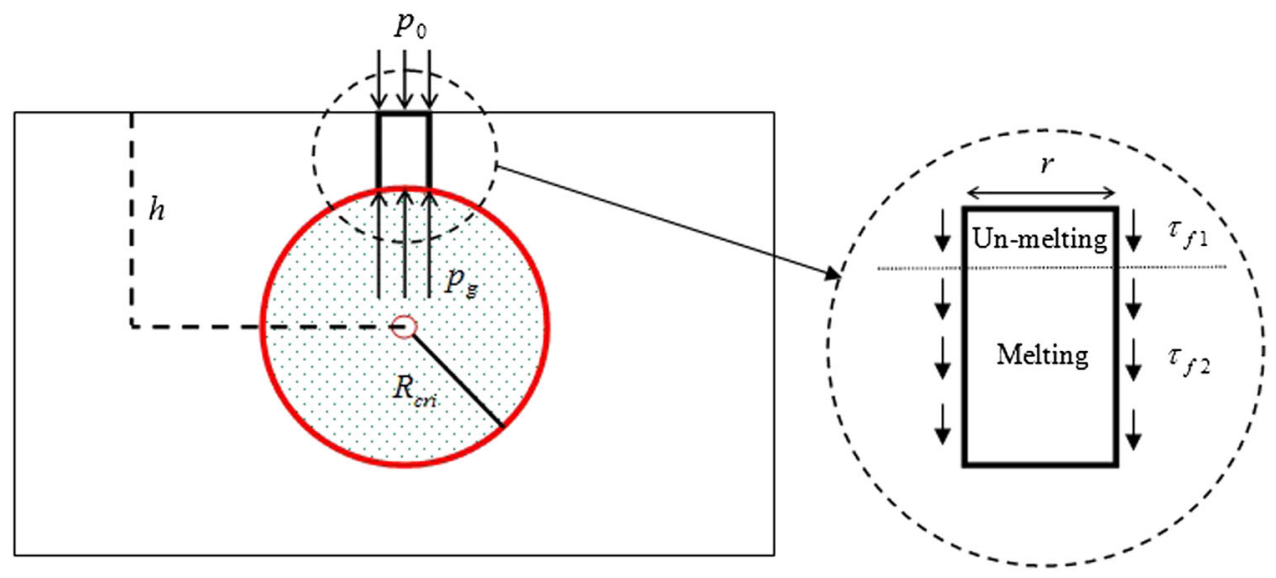

Figure 3. Critical status of outburst failures.

Because the thickness of the overlying layer is small, the strength is considered a constant. The resistance forces include:

(1) The gravity of the overlying layer:

$$
F_{G}=\bar{\rho} g \cdot\left(h-R_{c r i}\right) \cdot \frac{\pi \cdot d^{2}}{4}
$$

(2) The friction force:

$$
F_{S}=\tau_{f 1} \cdot \pi \cdot d \cdot\left(h-R_{c r i}\right) \cdot \xi+\tau_{f 2} \cdot \pi \cdot d \cdot\left(h-R_{c r i}\right) \cdot(1-\xi)
$$

Based on static force equilibrium, the critical outburst condition can be obtained approximately:

$$
F_{D} \geq F_{G}+F_{S}
$$

According to the shearing failure of soils, equation (29) can be reduced to:

$$
\frac{4 \cdot\left(\tau_{f 1} \cdot \xi+\tau_{f 2} \cdot(1-\xi)\right) \cdot\left(h-R_{c r i}\right) / d}{p_{g}-p_{0}} \leq 1-\frac{\bar{\rho} g \cdot\left(h-R_{c r i}\right)}{p_{g}-p_{0}}
$$

where $\xi$ is the melting fraction of overlying layer, $\tau_{f 1}$ and $\tau_{f 2}$ are the shear strengths of un-melting and melting fractions of over layer, respectively. If $4 \cdot\left(\tau_{f 1} \cdot \xi+\tau_{f 2} \cdot(1-\xi)\right) \cdot\left(h-R_{c r i}\right) / d$ is small enough, gas outburst occurs.

\section{RESULTS AND DISCUSSION}

For the heat transfer process, using the numerical simulation based on the data in Tables I and II, the dissociation fronts from the outburst times agree well with that of experiments (the maximum error is $8 \%$ ), verifying the decoupled analytical method is valid (Table IV).

In order to obtain the parameters of the shear strength of the overlying layer, six specimens of the sediment with $90 \%$ ice and after ice melting were prepared for un-drained and unconsolidated tri-axial tests under confining pressures of $25 \mathrm{kPa}, 50 \mathrm{kPa}$, and $100 \mathrm{kPa}$, respectively. The 
Table IV. Comparison of measured and experimental results.

\begin{tabular}{lcccccc}
\hline Conditions & \multicolumn{5}{c}{ Tests } \\
\cline { 2 - 7 } & 1 & 2 & 3 & 4 & 5 & 6 \\
\hline Temperature of heat $\left({ }^{\circ} \mathrm{C}\right)$ & 110 & 112 & 120 & 120 & 130 & 150 \\
Heating time (min) & 38 & 40.8 & 71.8 & 77 & 44.9 & 72.1 \\
Measured dissociation length (cm) & 7.5 & 8.0 & 9.8 & 9.0 & 9.0 & 10.8 \\
Simulated dissociation length $(\mathrm{cm})$ & 7.3 & 7.8 & 9.7 & 9.9 & 8.7 & 10.0 \\
Error $(\%)$ (measured - simulated)/ simulated & 3 & 3 & 2 & 9 & 3 & 8 \\
\hline
\end{tabular}

composition and parameters of soil skeleton are the same as those of the overlying layer in the outburst experiments as shown in Tables I and II.

The cohesion and internal friction angle of ice sediments and after ice melting are $1.2 \mathrm{MPa}$ and $0^{\circ}$, $4.6 \mathrm{kPa}$, and $2.3^{\circ}$ (the internal friction angle is not zero because of the volume shrinkage after hydrate dissociation), respectively, as shown in Figures 4 and 5.

For the criterion of gas outbursts, the ratio $A$ of the driving force and resistance forces is introduced in equation (30):

$$
A=\frac{\text { driving force }}{\text { resistance force }}=\frac{p_{g}-p_{0}}{\bar{\rho} g \cdot\left(h-R_{c r i}\right)+4 \cdot\left(\tau_{f 1} \cdot \xi+\tau_{f 2} \cdot(1-\xi)\right) \cdot\left(h-R_{c r i}\right) / d}
$$

When $A$ is given the value of 1 , according to the data from Table I and the parameters from Figure 5, the six groups of values of $\xi$ can be obtained from equation 31, i.e. $\xi=\{0.001,0,0.01,0.001,0.008$, $0.004\}$. The results show that most fraction of the overlying layer is heating, melting, and softening
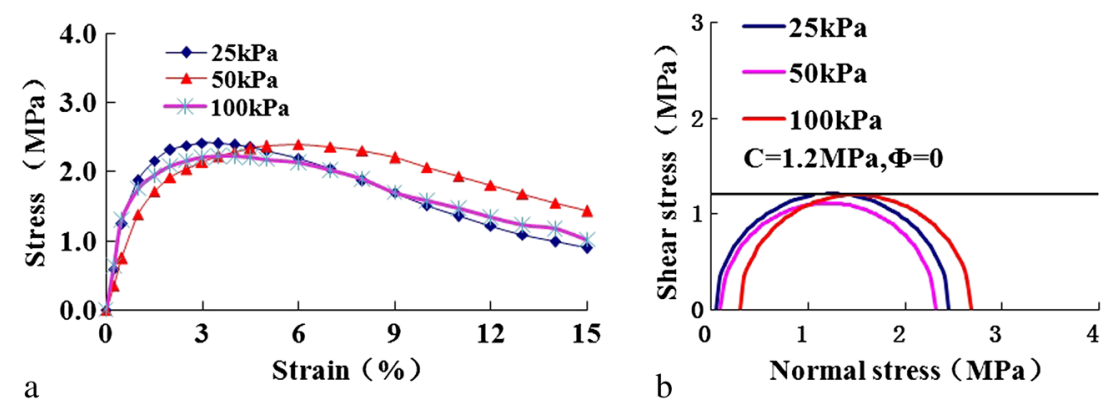

Figure 4. Stress-strain curves and Mohr circles of sediments with $90 \%$ ice, a. Stress-strain curve and b. Mohr circle.
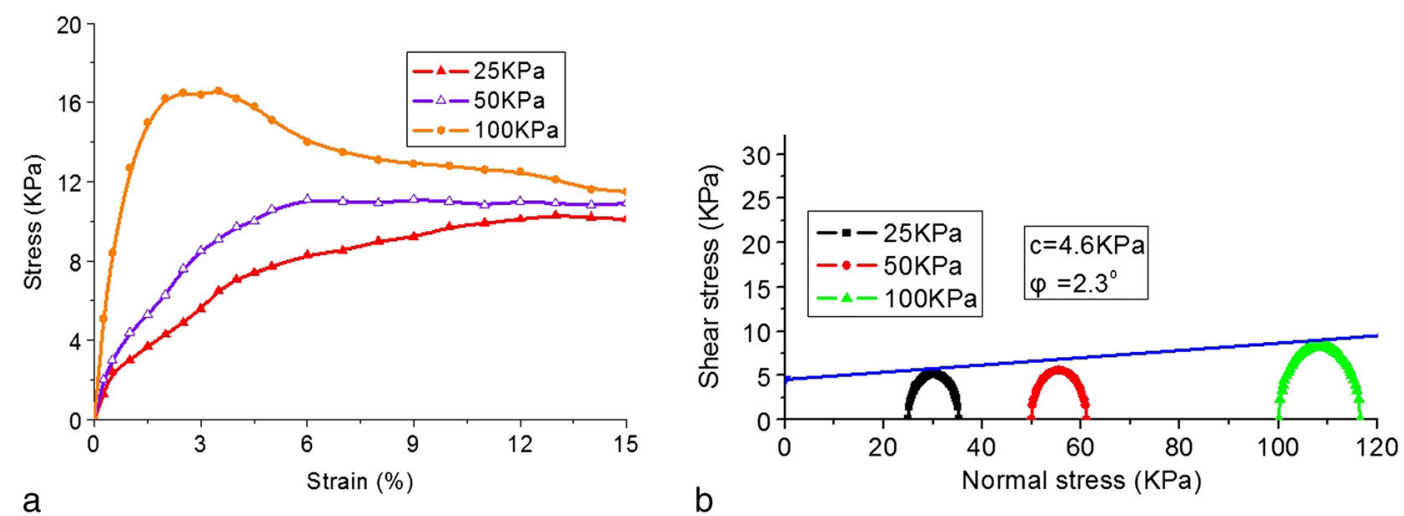

Figure 5. Stress-strain curves and Mohr's circles after ice melting, a. Stress-strain curve and b. Mohr circle. 
because of the penetration of gas and water. Consequently, the excess pore gas pressure could break through the overlying layer, leading to the gas outburst in sediments as small holes in the weak zone formed during hydrate dissociation. This is in agreement with the experimental observation that most of the sediments close to the outburst path of the overlying layer melt and soften after gas outbursts. If $\xi$ is known in practical engineering, the failure size $d$ could be obtained through upperbound or limit equilibrium analysis.

The conditions in the continental slope area in the South China Sea where hydrate bearing sediment exists and the experimental conditions in this study are compared to estimate whether there exists a possibility of gas outburst in situ. The water depth in the area is $1200 \mathrm{~m}$, the unit weight is $0.02 \mathrm{MPa} / \mathrm{m}$, the hydrate fraction is 0.2 , and the shear strength of the sediments is $20 \mathrm{MPa}$ [12] When a drilling hole that is filled with liquid at a temperature of $100{ }^{\circ} \mathrm{C}$ passes through the sediment, the hydrate is dissociated and excess pore pressure can be $0-100 \mathrm{MPa}$ if the gas remains in un-drained condition [29]. In laboratory experiments, the unit weight is $0.02 \mathrm{MPa} / \mathrm{m}$, the hydrate fraction is 0.4 , the height of overlying layer can be $0-60 \mathrm{~cm}$, and the shear strength of the overlying is between 0.005 and $1.2 \mathrm{MPa}$. The excess pore gas pressure is $0-0.6 \mathrm{MPa}$ after hydrate dissociation. The two key parameters, the dimensionless driving force and resistance in experimental conditions, can be in the same order of magnitude with those in in-situ.

Under in-situ condition:

$$
\begin{aligned}
& \min \left\{\frac{\bar{\rho} g h}{p_{g}-p_{0}}\right\}=0.3 \\
& \min \left\{\frac{\tau_{f}}{p_{g}-p_{0}}\right\}=0.2
\end{aligned}
$$

Under experimental condition:

$$
\begin{gathered}
\min \left\{\frac{\bar{\rho} g h}{p_{g}-p_{0}}\right\}=0 \\
\min \left\{\frac{\tau_{f}}{p_{g}-p_{0}}\right\}=0.01
\end{gathered}
$$

The comparison of controlling dimensionless parameters illustrates that the laboratory scale can simulate the in-situ condition although the THF hydrate sediments are used and the possibility of gas outburst in a well or pipe scale is non-negligible.

\section{CONCLUSIONS}

Gas outburst is observed in the laboratory experiments during the THF hydrate thermal dissociation. The physical mechanism is that heat transfer leads to the expansion of hydrate dissociation zone and the formation of excess pore gas pressure (driving force), and decreases the weight and the shear strength of the overlying layer (resistance).

A decoupled analytical method is presented based on the order of the characteristic times, heat transfer, and soil deformation. First, the thermal conduction considering three kinds of phase transformations in sediments, the slowest and controlling process, is analyzed. Second, the empirical 
critical condition for outburst is derived based on a simple mechanical equilibrium limit analysis. The following observation and conclusions are made from this study.

(1) An axis asymmetrical model of heat transfer containing three kinds of phase transformations and different zones is presented. Through the simulations, the THF hydrate dissociation front at the outburst times agrees well with that of experiments, indicating that the decoupled analytical method is valid.

(2) When a shear failure of the weak zone in overlying layer is assumed, the empirical critical condition for gas outburst after THF hydrate dissociation is obtained. Generally, once the driving force exceeds the resistance, the overlying layer is fractured and destroyed, and the gas outbursts with sediments in the dissociation zone when the excess pore gas pressure and energy is higher than the resistance's work of the overlying layer. The experimental results are in agreement with the theoretical analysis.

The engineering application of this study is discussed based on a dimensionless analysis of geometric and mechanical similarities. It should be noted that determining the extent of damages requires the consideration of the dynamic and seepage effect and is worth of further study.

\section{ACKNOWLEDGEMENT}

This study is supported by the National Natural Science Foundation of China under grant nos. 11102209 and 51239010 .

\section{REFERENCES}

1. Sloan ED. Clathrate Hydrates of Natural Gases. Marcel Dekker Inc.: New York, 1998.

2. Guerin G, Goldberg D, Meltser A. Characterization of in-situ elastic properties of gas hydrate bearing sediments on the Blake Ridge. Journal of Geophysical Research 1999; 104(B8):17781-17795.

3. Kvenvolden KA, Lorenson TD. The global occurrence of natural gas hydrate. Geophysical Monograph 2001; 124:3-18.

4. Kono HO, Narasimhan S, Song F, Smith DH. Synthesis of methane gas hydrate in porous sediments and its dissociation by depressurizing. Powder Technology 2002; 122:239-246.

5. Riedel M, Bellefleur G, Mair S, Brent TA, Dallimore SR. Amplitude and frequency anomalies in regional 3D seismic data surrounding the Mallik 5 L-38 research site, Mackenzie Delta, Northwest Territories, Canada. Geophysics 2006; 71(6):B183-191.

6. Xu W, Germanovich LN. Excess pore pressure resulting from methane hydrate dissociation in marine sediments: a theoretical approach. Journal of Geophysical Research 2006; 111:B011104. DOI: 10.1029/2004JB003600

7. Kwon TH, Cho GC, Santamarina JC. Gas hydrate dissociation in sediments: pressure-temperature evolution. Geochemistry, Geophysics, Geosystems 2008; 9:Q03019. DOI: 10.1029/2007GC001920

8. Bard E, Hamelin B, Fairbanks RG, Zindler A. Calibration of the C-14 timescale over the past 30,000 years using mass-spectrometric U-TH ages from barbadoscorals. Nature 1990; 345:405-410.

9. Dickens GR, Quinby-Hunt MS. Methane hydrate stability in seawater. Geophysical Research Letters 1994; 21(19):2115-2118.

10. Milkov AV. Worldwide distribution of submarine mud volcanoes and associated gas hydrates. Marine Geology 2000; 167:29-42.

11. Sultan N, Cochonat P, Foucher JP, Mienert J. Effect of gas hydrates melting on seafloor slope instability. Marine Geology 2004b; 213:379-401.

12. Zhang XH, Lu XB, Li QP. Formation of layered fracture and outburst during gas hydrate dissociation. Journal of Petroleum Science and Engineering 2011; 76(3-4):212-216.

13. Bugge T, Befring S, Belderson RH, Eidvin T, Jansen E, Kenyon NH, Holtedahl H, Sejrup HP. A giant three-stage submarine slide off Norway. Geo-Marine Letters 1987; 7:191-198.

14. Bouriak S, Vanmste M, Saoutkine A. Inferred gas hydrates and clay diapers near the Storegga slide on the southern edge of the V申ring Plateau, offshore Norway. Marine Geology 2000; 163:125-148.

15. Sultan N, Foucher JP, Cochonat P, Bourillet JF, Ondreas H, Cauquil E, Grauls D. Dynamics of gas hydrate: case of Congo continental slope. Marine Geology 2004a; 206:1-18.

16. Sassoon D. Did deepwater methane hydrates cause the BP gulf explosion? 20 May 2010. http://www.guardian.co.uk/ environment/2010/may/20/deepwater-methane-hydrates-bp-gulf

17. Rutqvist J, Moridis GJ. Numerical studies on the geomechanical stability of hydrate-bearing sediments. SPE Journal 2009; 14(2):267-282. SPE-126129-PA. DOI: 10.2118/126129-PA

18. Kimoto S, Oka F, Fushita T. A chemo-thermo-mechanically coupled analysis of ground deformation induced by gas hydrate dissociation. International Journal of Mechanical Science 2010; 2010(52):365-376. 
19. Klar A, Soga K, Ng MYA. Coupled deformation-flow analysis for methane hydrate extraction. Geotechnique 2010; 60(10):765-776.

20. Klar A, Uchida S, Soga K, Yamamoto K. Explicitly coupled thermal flow mechanical formulation for gas-hydrate sediments. SPE Journal 2013; 18(2):196-206. SPE-162859-PA. DOI: 10.2118/162859-PA

21. Uchida S, Soga K, Klar A, Yamamoto K. Geomechanical study of the Mallik gas hydrate production field trials. Bulletin of the Geological Survey Canada 2012; 601:191-204.

22. Tohidi B, Anderson R, Clennell MB, Burgass RW, Biderkab AB. Visual observation of gas hydrate formation and dissociation in synthetic porous media by means of glass micromodels. Geology 2001; 29(9):867-870.

23. Jones KW, Kerkar PB, Mahajan D, Lindquist WB, Feng H. Microstructure of natural hydrate host sediments. Nuclear Instruments and Methods in Physics Research B 2007; 261:504-507.

24. Koh CA. Towards a fundamental understanding of natural gas hydrates. Chemical Society Reviews 2002; 31:157-167.

25. Zhang XH. A study of the weakening and failure in thermal-induced dissociation of gas hydrate-bearing sediments. Doctor thesis (in Chinese), Beijing, 2010.

26. Zhang XH, Lu XB, Li QP, Yao HY. Thermally induced evolution of phase transformations in gas hydrate sediment. Science China Physics, Mechanics\& Astronomy 2010; 53(8):1-6. doi:10.1007/s11433-010-4060-8.

27. Chaouch A, Briaud JL. Post melting behavior of gas hydrates in soft ocean sediments. In: Proceedings of the 29th Offshore Technology Conference. Texas: Offshore Technology Conference, 1997; 217-224

28. Waite WF, Santamarina JC, Cortes DD, Dugan B, Espinoza DN, Germaine J, Jang J, Jung JW, Kneafsey TJ, Shin H, Soga K, Winters WJ, Yun TS. Physical properties of hydrate-bearing sediments. Reviews of Geophysics 2009; RG4003/2009, 47:1-38

29. Xu W, Germanovich LN. Reply to comment by Nabil Sultan on "Excess pore pressure resulting from methane hydrate dissociation in marine sediments: A theoretical approach". Journal of Geophysical Research 2007; 112: B02104. DOI: 10.1029/2006JB004722 